\title{
Hubungan Keterlambatan Kedatangan Dokter terhadap Kepuasan Pasien di Instalasi Rawat Jalan
}

\section{Doctors' Delays on Arrival to Patient Satisfaction Relationship in Outpatient Units}

\author{
David ${ }^{1}$, Tita Hariyanti ${ }^{1}$, Erika Widayanti $L^{2}$ \\ ${ }^{1}$ Program Studi Magister Manajemen Rumah Sakit Fakultas Kedokteran Universitas Brawijaya Malang \\ ${ }^{2}$ Rumah Sakit Muhammadiyah Ahmad Dahlan Kota Kediri
}

\begin{abstract}
ABSTRAK
Kepuasan pasien merupakan tujuan utama pelayanan kesehatan. Salah satu indikator mutu pelayanan di instalasi rawat jalan rumah sakit adalah ketepatan kedatangan dokter sesuai dengan waktu yang telah ditentukan oleh rumah sakit. Tujuan penelitian ini adalah untuk menilai pengaruh kepuasan pasien di instalasi rawat jalan terhadap keterlambatan jam kedatangan dokter sesuai dengan jadwal yang tertera. Penelitian ini menggunakan metode kuantitatif korelasional dengan pendekatan cross sectional. Instrumen penelitian menggunakan kuesioner daftar tilik yang telah dilakukan uji validitas dan reliabilitas dengan tambahan pertanyaan terbuka untuk saran. Secara keseluruhan pasien yang puas hanya $14 \%$ dan cukup puas $60 \%$. Ketidakpuasan tertinggi (>50\%) didapatkan pada aspek keterlambatan dokter dan permintaan maaf dari dokter ketika terlambat. Hasil menunjukkan hubungan yang kuat antara kepuasan pasien dengan ketepatan jam kedatangan dokter di instalasi rawat jalan rumah sakit $(p<0,001)$. Beberapa solusi untuk meningkatkan kepuasan pasien adalah dengan meningkatkan kenyamanan ruang tunggu dan melakukan penjadwalan ulang jam praktek dokter.
\end{abstract}

Kata Kunci: Kepuasan pasien, keterlambatan dokter

\begin{abstract}
Patient satisfaction is a primary goal of health care. One of the indicators of service quality in hospital outpatient unit is in accordance with the accuracy of the doctor's arrival that has been set by the hospital schedule. The purpose of this study was to assess the effect of patient satisfaction in outpatient unit over the lateness of the doctor's arrival according to the schedule listed. This study uses a quantitative correlation method with cross-sectional approach. The research instrument used checklist questionnaires whose validity and reliability have been tested with additional open questions for suggestions. Overall, satisfied patients were only $14 \%$ and $60 \%$ were fairly satisfied. The highest dissatisfaction (>50\%) was found in the aspect of doctor's delay and apology from the doctor when coming late. This study shows a strong relationship between patients' satisfaction with the accuracy of the doctor's arrival in the outpatient unit $(p<0,001)$. Several solutions to improve patient satisfaction are improving the comfort of the lounge and rescheduling doctors' office hours.
\end{abstract}

Keywords: Lateness of the doctor's arrival, patient satisfaction

Jurnal Kedokteran Brawijaya, Vol. 28, Suplemen No. 1, 2014: David. Program Studi Magister Manajemen Rumah Sakit Fakultas Kedokteran Universitas Brawijaya Malang, Jl. Veteran Malang 65142 Tel. (0341)568989Email:dr.david91@yahoo.co.id 


\section{PENDAHULUAN}

Rumah sakit merupakan suatu institusi pelayanan kesehatan yang padat tantangan dengan fungsi utamanya memberikan pelayanan promotif, preventif, kuratif dan rehabilitatif. Rumah sakit swasta maupun pemerintah saat ini sedang berkembang dalam sisi jumlah dan macam pelayanan spesialistik yang ditawarkan dengan mengutamakan layanan prima.

Dimensi layanan prima yang perlu diperhatikan oleh penyedia jasa kesehatan yaitu nyata (tangible). Tangible adalah sesuatu yang bersifat fisik dan fasilitas yang ditawarkan oleh rumah sakit. Jaminan (assurance) menunjukkan, kemampuan dalam menyakinkan pelanggan tentang jaminan pelayanan yang akan mereka dapatkan sehingga akan memunculkan kepercayaan pasien. Kehandalan (reliability) merupakan, kemampuan dalam memberikan kepastian pelayanan. Ketanggapan (responsiveness) menunjukkan, kemampuan dalam memberikan pelayanan dengan cepat dan bertanggung jawab dalam merespon. Empati menunjukkan kemampuan rumah sakit dalam memberikan perhatian dan melayani dengan tulus dan ikhlas (1). Salah satu bentuk empati adalah menjalin komunikasi yang baik. Ikatan antara dokter atau paramedis dengan pasien yang dirawatnya akan terjadi dengan adanya komunikasi yang baik. Komunikasi yang baik adalah edukasi konsumen, dalam hal ini dokter memberikan keterangan yang jelas tentang penyakit, tindakan yang akan diberikan serta prognos penyakit yang dideritanya. Kelemahan dokter di Indonesia dinilai masih kurang dalam pelayanan edukasi konsumen terhadap para pasiennya karena keterbatasan waktu, sehingga menjadi salah satu faktor penyebab banyaknya orang Indonesia memilih berobat keluar negeri (2). Selain komunikasi diperlukan jaminan terhadap segala hal yang berhubungan dengan layanan kesehatan dengan ditetapkannya Standar Pelayanan Minimal (SPM) rumah sakit.

Penentuan SPM dengan ditetapkannya Keputusan menteri kesehatan nomor 129/Menkes/SK/II/2008 tentang Standar Pelayanan Minimal rumah sakit telah menjadi keharusan di setiap layanan kesehatan yang ada untuk menjamin kualitas layanan prima sebagai hasil akhir dari produk kesehatan yang ditawarkan (3). Setiap unit pelayanan dan manajemen rumah sakit telah ditentukan SPM sebagai acuan standar pelayanan yang harus dipenuhi (4). Salah satu indikator SPM rawat jalan yang berhubungan dengan waktu tunggu adalah lama waktu tunggu $\leq 60$ menit.

Waktu tunggu yang lama merupakan salah satu permasalahan yang banyak ditemukan di instalasi rawat jalan rumah sakit. Data laporan tahunan rumah sakit tentang angka keterlambatan dokter terhadap jam praktek sebesar $8,7 \%$ dari target 5\% SPM rumah sakit. Waktu tunggu merupakan salah satu komponen yang dirasakan langsung oleh pelanggan yang tidak hanya mencerminkan waktu tunggu sebenarnya tetapi juga lebih dipengaruhi persepsi pasien. Penelitian ini dilakukan untuk mengkaji faktor yang mempengaruhi waktu tunggu sebagai dasar bagi perbaikan manajemen pelayanan rawat jalan di rumah sakit.

\section{METODE}

Penelitian ini merupakan penelitian kuantitatif korelasional dengan desain penelitian cross sectional untuk mencari hubungan antara kepuasan pasien sebagai variabel bebas dengan lamanya waktu tunggu akibat keterlambatan dokter sebagai variabel terikat.

Penelitian dilakukan di instalasi rawat jalan rumah sakit Muhammadiyah Ahmad Dahlan Kota Kediri pada bulan November 2013. Populasi untuk penelitian diambil dari pasien yang datang berkunjung ke rawat jalan poliklinik spesialis sejumlah 48 orang dengan teknik accidental sampling. Peneliti mengambil data dari subjek yang ditemuinya saat itu dalam jumlah secukupnya (5-7). Pengumpulan data diperoleh dari data primer dan data sekunder. Data primer berupa kuesioner yang diisi oleh responden penelitian serta data sekunder berupa arsip rumah sakit sebagai bahan penyusunan permasalahan. Kuesioner yang dipakai adalah sistem daftar tilik dengan pilihan jawaban sangat tidak puas (STP), tidak puas (TP), puas $(P)$ dan sangat puas (SP) dengan menggunakan skala Likert 1 sampai 4 disertai pertanyaan terbuka untuk saran. Selanjutnya dilakukan tabulasi kuesioner untuk dilakukan uji reliabilitas serta validitas kuesioner karena belum pernah dipakai sebelumnya.

Setelah dilakukan pengolahan data langkah selanjutnya adalah melakukan analisis data dengan menggunakan program SPSS. Analisis univariat dilakukan untuk mendeskripsikan karakter responden, kedatangan dokter dan tingkat kepuasan pasien berdasarkan 25 pertanyaan kuesioner. Analisis bivariat dilakukan dengan menggunakan Chi-Square.

\section{HASIL}

\section{Karakteristik Demografi Responden}

Berdasarkan hasil penelitian pada 48 orang responden, dapat diketahui bahwa 56,3\% merupakan responden perempuan, 43,8\% sisanya adalah responden laki-laki. Perbandingan persentase antara responden perempuan dan laki-laki yang diambil tidak terlalu berbeda jauh.

Dari 48 orang responden diketahui $45,8 \%$ responden berpendidikan SMU, 22,9\% responden berpendidikan sarjana (perguruan tinggi), sedangkan responden lainnya mempunyai tingkat pendidikan yang lebih rendah. Pekerjaan responden sebanyak $50 \%$ bekerja sebagai pegawai swasta, sedangkan responden lainnya mempunyai jenis pekerjaan yang bervariasi. Untuk usia responden 39,6\% berumur antara 17-30 tahun, 22,9\% berumur antara 31-40 tahun, sedangkan responden lainnya mempunyai umur yang lebih tua.

Tabel 1. Gambaran karakteristik demografi responden

\begin{tabular}{llcc}
\hline \multicolumn{2}{c}{ Karakteristik Demografi } & Frekuensi & Persentase (\%) \\
\hline \multirow{2}{*}{ Jenis kelamin } & L & 21 & $43,8 \%$ \\
& P & 27 & $56,3 \%$ \\
& Tidak lulus SD & 2 & $4,2 \%$ \\
Tingkat & SD & 5 & $10,4 \%$ \\
pendidikan & SMP & 8 & $16,7 \%$ \\
& SMU & 22 & $45,8 \%$ \\
& Perguruan & 11 & $22,9 \%$ \\
& Tinggi & 6 & $12,5 \%$ \\
& Tidak bekerja & & \\
\hline
\end{tabular}


Tabel 1. Gambaran karakteristik demografi responden (Lanjutan)

\begin{tabular}{llcc}
\hline \multicolumn{1}{c}{ Karakteristik Demografi } & Frekuensi & Persentase (\%) \\
\hline \multirow{4}{*}{ Jenis } & Pegawai swasta & 24 & $50,0 \%$ \\
pekerjaan & PNS & 1 & $2,1 \%$ \\
& Petani & 8 & $16,7 \%$ \\
& TNI/POLRI & 1 & $2,1 \%$ \\
& Buruh & 3 & $6,3 \%$ \\
& Lain-lain & 5 & $10,4 \%$ \\
Umur & $17-30$ th & 19 & $39,6 \%$ \\
responden & $31-40$ th & 11 & $22,9 \%$ \\
& $41-50$ th & 8 & $16,7 \%$ \\
& $51-60$ th & 7 & $14,6 \%$ \\
& Lebih dari 61 th & 3 & $6,3 \%$ \\
\hline
\end{tabular}

\section{Tingkat Kepuasan Pasien}

Berdasarkan Tabel 2 dapat diketahui bahwa 70,8\% responden menjawab puas atas pernyataan "petugas loket pendaftaran cepat memberikan pelayanan saat pasien datang". Sebanyak $45,8 \%$ responden menjawab tidak puas atas pernyataan "dokter spesialis selalu datang tepat waktu sesuai dengan jam praktek yang tertera". Sebanyak $45,8 \%$ responden menjawab tidak puas atas pernyataan "pasien memperoleh permintaan maaf dari dokter yang terlambat datang dalam memberikan pelayanan". Sebanyak $58,3 \%$ responden menjawab puas atas pernyataan "pasien selalu mendapatkan penjelasan penyakit yang sedang diderita dari dokter pemeriksa". Sebanyak $66,7 \%$ responden menjawab puas atas pernyataan "pasien selalu mendapatkan informasi dari petugas pendaftaran bila dokter terlambat datang". Kemudian $52,1 \%$ responden yang menjawab puas atas pernyataan "ruang tunggu pasien nyaman". Berdasarkan hasil survei, diperoleh informasi bahwa dari 48 orang responden, 31 orang $(64,6 \%)$ responden menyatakan bahwa kedatangan dokter spesialis untuk menangani pasien tergolong tidak tepat waktu.

Perhitungan kategori tingkat kepuasan pasien dengan menggunakan kriteria menurut Arikunto (15) sebagai berikut: tidak puas bila $<40 \%$, kurang puas bila $40-55 \%$, cukup puas bila $56-75 \%$ dan Puas bila $76-100 \%$. Tabel 3 menunjukkan tingkat kepuasan pasien dengan menggunakan persentase dari total skor. Secara kumulatif sebanyak 29 orang $(60,4 \%)$ responden menilai cukup puas terhadap pelayanan poliklinik rumah sakit, $14,6 \%$ responden menilai puas dengan kedatangan dokter spesialis untuk menangani pasien di RS, sedangkan responden lainnya masih tergolong kurang puas $(20,8 \%)$ dan tidak puas (4,2\%). Gambaran ini menunjukkan masih kecilnya proporsi pelanggan yang merasa puas terhadap pelayanan di rumah sakit.

Tabel 3. Distribusi frekuensi tingkat kepuasan pasien

\begin{tabular}{ccc}
\hline Tingkat Kepuasan & Frekuensi & Persentase (\%) \\
\hline Tidak puas & 2 & $4,2 \%$ \\
Kurang puas & 10 & $20,8 \%$ \\
Cukup Puas & 29 & $60,4 \%$ \\
Puas & 7 & $14,6 \%$ \\
Total & 48 & $100 \%$ \\
\hline
\end{tabular}

Sumber: Data primer yang diolah

\section{Hubungan Tingkat Kepuasan dan Waktu Kedatangan Dokter}

Dari 31 orang responden (Tabel 4) yang menyatakan bahwa kedatangan dokter spesialis untuk menangani pasien tergolong tidak tepat waktu, ada sebanyak 6,5\% yang tergolong tidak puas dengan pelayanan dokter, $32,3 \%$ tergolong kurang puas, namun $61,3 \%$ responden mrnyatakan cukup puas. Pada 17 orang responden yang menyatakan bahwa kedatangan dokter spesialis untuk menangani pasien tergolong tepat waktu, sebanyak 58,8\% responden tergolong cukup puas dengan pelayanan dokter, bahkan $41,2 \%$ responden lainnya tergolong puas. Dapat disimpulkan pada,responden yang menyatakan dokter datang tepat waktu lebih banyak yang menyatakan puas dibandingkan pada pasien yang menyatakan dokter tidak tepat waktu.

Tabel 2. Gambaran kepuasan pasien di setiap komponen

\begin{tabular}{|c|c|c|c|c|c|c|c|c|c|}
\hline \multirow{3}{*}{ No. } & \multirow{3}{*}{ Komponen Kepuasan } & \multicolumn{8}{|c|}{ Tingkat Kepuasan } \\
\hline & & \multicolumn{2}{|c|}{ STP } & \multicolumn{2}{|c|}{ TP } & \multicolumn{2}{|c|}{$\mathbf{P}$} & \multicolumn{2}{|c|}{ SP } \\
\hline & & $\mathbf{F}$ & $\%$ & $\mathbf{F}$ & $\%$ & $\mathbf{F}$ & $\%$ & $\mathbf{F}$ & $\%$ \\
\hline 1 & $\begin{array}{l}\text { Petugas cepat memberikan } \\
\text { pelayanan saat pasien datang }\end{array}$ & 1 & $2,1 \%$ & 4 & $8,3 \%$ & 34 & $70,8 \%$ & 9 & $18,8 \%$ \\
\hline 2 & $\begin{array}{l}\text { Dokter spesialis datang tepat } \\
\text { waktu }\end{array}$ & 9 & $18,8 \%$ & 22 & $45,8 \%$ & 15 & $31,3 \%$ & 2 & $4,2 \%$ \\
\hline 3 & $\begin{array}{l}\text { Pasien memperoleh maaf } \\
\text { saat dokter terlambat datang }\end{array}$ & 9 & $18,8 \%$ & 22 & $45,8 \%$ & 15 & $31,3 \%$ & 2 & $4,2 \%$ \\
\hline 4 & $\begin{array}{l}\text { Pasien mendapatkan } \\
\text { penjelasan penyakit }\end{array}$ & 3 & $6,3 \%$ & 11 & $22,9 \%$ & 28 & $58,3 \%$ & 6 & $12,5 \%$ \\
\hline 5 & $\begin{array}{l}\text { Pasien mendapatkan } \\
\text { informasi bila dokter } \\
\text { terlambat datang }\end{array}$ & 3 & $6,3 \%$ & 9 & $18,8 \%$ & 32 & $66,7 \%$ & 4 & $8,3 \%$ \\
\hline 6 & Ruang tunggu pasien nyaman & 3 & $6,3 \%$ & 16 & $33,3 \%$ & 25 & $52,1 \%$ & 4 & $8,3 \%$ \\
\hline
\end{tabular}

Keterangan: $\mathrm{STP}=$ Sangat tidak puas; $\mathrm{TP}=$ tidak puas; $\mathrm{P}=\mathrm{Puas} ; \mathrm{SP}=\mathrm{Sangat}$ puas 
Hasil uji Chi-Square $\left.{ }^{2}=19,356 ; p=0,000\right)$ menunjukkan ada hubungan bermakna antara tingkat kepuasan pasien dengan ketepatan waktu kedatangan dokter untuk menangani pasien di Unit Rawat Jalan. Ketepatan waktu kedatangan dokter spesialis dalam melayani pasien di Unit Rawat Jalan akan semakin meningkatkan kepuasan pasien. Sebaliknya, apabila dokter datang tidak tepat waktu untuk melayani pasien di Unit Rawat Jalan, maka hal ini akan semakin menurunkan kepuasan pasien.

Tabel 4. Hubungan tingkat kepuasan pasien dengan ketepatan waktu kedatangan

\begin{tabular}{cccccc}
\hline \multirow{2}{*}{$\begin{array}{c}\text { Kedatangan } \\
\text { Dokter }\end{array}$} & \multicolumn{4}{c}{ Tingkat Kepuasan Pasien } & \multirow{2}{*}{ Total } \\
\cline { 2 - 5 } & $\begin{array}{c}\text { Tidak } \\
\text { puas }\end{array}$ & $\begin{array}{c}\text { Kurang } \\
\text { puas }\end{array}$ & $\begin{array}{c}\text { Cukup } \\
\text { puas }\end{array}$ & Puas & \\
\hline Tidak tepat & 2 & 10 & 19 & 0 & 31 \\
waktu & $6,5 \%$ & $32,3 \%$ & $61,3 \%$ & $41,2 \%$ & $100,0 \%$ \\
Tepat waktu & 0 & 0 & 10 & 7 & 17 \\
& $0,0 \%$ & $0,0 \%$ & $58,8 \%$ & $41,2 \%$ & $100,0 \%$ \\
Total & 2 & 10 & 29 & 7 & 48 \\
& $4,2 \%$ & $20,8 \%$ & $60,4 \%$ & $14,6 \%$ & $100,0 \%$ \\
\hline
\end{tabular}

\section{DISKUSI}

Hasil penelitian menunjukkan bahwa keterlambatan waktu kedatangan dokter dalam memberikan pelayanan mempengaruhi kepuasan pasien di instalasi rawat jalan rumah sakit. Bila dokter terlambat datang dalam memberikan pelayanan maka kepuasan pasien akan turun tetapi sebaliknya bila dokter datang tepat waktu akan meningkatkan kepuasan pasien. Hal ini sesuai dengan penelitian yang telah dilakukan oleh Kapustiak bahwa kepedulian terhadap waktu tunggu sangat penting untuk penyedia jasa kesehatan dengan cara mendistribusikan ulang waktu konsultasi bukan pada jam sibuk, memberikan edukasi kepada pasien tentang pentingnya ketetapan waktu konsultasi serta membuat jadwal konsultasi yang realistik. Memperpendek waktu tunggu pasien juga bisa dilakukan dengan cara meningkatkan kecepatan mencari data pasien di unit rekam medik dengan menggunakan tekhnologi komputer (6). Waktu tunggu pasien yang sesuai dengan SPM rumah sakit akan dapat meningkatkan kualitas layanan serta kepuasan pasien (10).

Menurut Candra dalam Khairani, salah satu indikator kepuasan pasien adalah waktu tunggu, waktu tunggu yang lama terhadap pelayanan medis maupun non medis pada unit rawat jalan dan rawat inap akan mengurangi

\section{DAFTAR PUSTAKA}

1. Yunarto TS dan Dwiyanto BM. Analisis Pengaruh Kualitas Layanan terhadap Kepuasan Pasien Rawat Inap di Rumah Sakit Umum Derah (RSUD) Tugurejo. [Tesis]. Universitas Diponegoro, Semarang. 2011.

2. Richard SD dan Hanafi I. Nurse Interpersonal Communication Skills Influence the Increasing of Patient Satisfaction. Jurnal Penelitian STIKES RS Baptis Kediri. 2013; 5(2): 155-166.

3. Kuntjoro T dan Djasri H. Standar Pelayanan Minimal Rumah Sakit sebagai Persyaratan Badan Layanan kepuasan pasien (5). Masalah yang sering muncul diinstalasi rawat jalan adalah lamanyawaktu tunggu penyampaian data rekam medis pasien ke meja dokter, sehinggadiperlukan sistem informasi manajemen rumah sakit yang bagus untuk mempercepat proses pencarian data pasien (6). Masalah utama lain yang sering terjadi di sebagian besar rumah sakit di Indonesia adalah lamanya waktu tunggu akibat keterlambatan kedatangan dokter yang tidak sesuai dengan jadwal pelayanan poliklinik (7).

Waktu tunggu adalah keseluruhan waktu yang dihabiskan oleh pasien dalam menunggu suatu layanan rawat jalan mulai dari pertama kali pasien melakukan pendaftaran di bagian pendaftaran hingga pemeriksaan pasien oleh dokter, dan waktu yang berlalu antara waktu perjanjian yang telah ditetapkan hingga pasien mendapatkan evaluasi (8). Keterlambatan ini terutama terjadi di setiap rumah sakit yang tidak mempunyai dokter tetap, hal ini di akibatkan oleh kesibukan dokter, ketidak sesuaian pengaturan jam praktek, serta lemahnya peraturan yang mengatur jumlah tempat praktek seorang dokter. Penelitian kepuasan pasien pada pasien rawat jalan di rumah sakit di Uganda menyatakan bahwa dengan lama waktu tunggu lebih dari 2 jam dapat menurunkan kepuasan pasien (9).

Waktu tunggu yang lama akan dapat menurunkan kepuasan pasien karena terjadi kesenjangan antara expected service dan perceived service. Kepuasan pasien dipengaruhi oleh kualitas layanan yang tergantung pada kemampuan penyedia jasa dalam memenuhi harapan konsumen secara konsisten (10). Kualitas layanan berpengaruh signifikan terhadap kepuasan konsumen, kepuasan konsumen berpengaruh signifikan terhadap loyalitas, ternyata kualitas layanan juga berpengaruh langsung terhadap loyalitas (11). Beberapa hal menarik dalam penelitian yang dilakukan pada anak di bawah lima tahun (balita) di unit rawat jalan anak di Afganistan adalah rendahnya kualitas layanan dipengaruhi oleh pemeriksaan pasien dan konseling, layanan yang diberikan oleh perawat perempuan lebih baik bila dibandingkan perawat laki laki, dokter memberikan layanan lebih baik bila dibandingkan rumah sakit lain (12).

Kepuasan pasien akan kualitas pelayanan yang paripurna mempengaruhi loyalitas pasien dalam pemanfaatan ulang fasilitas kesehatan rumah sakit (13). Rumah sakit perlu membina hubungan baik dengan pasien dengan memenuhi kebutuhan mereka akan pelayanan prima sehingga menjadikan mereka pelanggan setia baik itu untuk kepentingan mereka pribadi ataupun dalam bentuk rekomendasi (word of mouth) kepada sanak saudara, teman dan tetangga (14).

Umum dan Sarana Peningkatan Kinerja. Jurnal Manajemen Pelayanan Kesehatan. 2007; 10(1): 03-10.

4. Departemen Kesehatan Republik Indonesia. Keputusan Menteri Kesehatan Republik Indonesia Nomor: 129/MENKES/SK/II/2008 Tentang Standar Pelayanan Minimal Rumah Sakit (SPM) 2008. Jakarta; Dinas Kesehatan RI; 2008.

5. Khairani L, Manjas M, dan Fendy R. Faktor-faktor yang Mempengaruhi Kepuasan Pasien Rawat Jalan RSUD Pasaman Barat. [Tesis]. Universitas Andalas, Padang. 2011. 
6. Andriyani L. Sistem Informasi Pendaftaran Pasien Rawat Jalan di Rumah Sakit dengan Menggunakan Program Komputer. [Skripsi]. Universitas Komputer Indonesia, Bandung. 2009.

7. Sulistyorini C, Lestari T, dan Rohmadi. Tinjauan Faktor Penyebab Waktu Tunggu Pelayanan Pendaftaran Pasien Umum Rawat Jalan di Rumah Sakit Umum Daerah Sragen. Jurnal Kesehatan. 2008; 2(1): 56-69.

8. Kapustiak J and Ling H. Evaluation of Patient Waiting Times at an Academic Ophthalmology Clinic. The Journal of Medical Practice Management. 2000; 15(5): 228-233.

9. Nabbuye-Sekandi J, Makumbi FE, Kasangaki A, et al. Patient Satisfaction with Services in Outpatient Clinics at Mulago Hospital, Uganda. International Journal for Quality in Health Care. 2011; 23(5): 516-523.

10. Tjiptono F. Manajemen Jasa. Yogyakarta: Andi; 2000.
11. Cronin J Jr and Taylor SA. Measuring Service Quality: Reexamination and Extension. Journal of Marketing. 1992; 56: 55-68.

12. Lind A, Edward A, Bonhoure P, et al. Quality of Outpatient Hospital Care for Children Under 5 Years in Afghanistan. International Journal for Quality in Health Care. 2011; 23(2): 108-106.

13. Solikhah. Hubungan Kepuasan Pasien dengan Minat Pasien dalam Pemanfaatan Ulang Pelayanan Pengobatan. Jurnal Manajemen Pelayanan Kesehatan. 2008; 11(4): 192-199.

14. Trarintya MAP. Pengaruh Kualitas Pelayanan terhadap Kepuasan dan Word of Mouth. [Tesis]. Universitas Udayana, Denpasar. 2011.

15. Arikunto S. Prosedur Penelitian: Suatu Pendekatan dan Praktik. Edisi Revisi. Jakarta: Rineka Cipta; 2002. 